\title{
Formation of Silicon from Shirasu Volcanic Ash Using Solar Furnace
}

\author{
K. Hatakeyama, H. Kaneko, and K. Nishioka
}

\begin{abstract}
Silicon was prepared from Shirasu volcanic ash using solar furnace. The solar furnace was composed from two parts; Fresnel lens and reacting furnace. Fresnel lens was used to concentrate sunlight onto the reacting furnace where the sample was put on. The sample was made from silica and silicon carbide formed using Shirasu volcanic ash, and placed in the carbon crucible inside the reacting furnace. By using light of sun concentrated with Fresnel lens, the sample was irradiated for 3.5 hours and the furnace was left until it cooled down to room temperature. Both irradiating and cooling processes were done under argon atmosphere. After the experiment, the sample was evaluated by $X$-ray diffraction. The sample was found to have produced the Si component.
\end{abstract}

Index Terms - Silica, silicon, solar furnace, volcanic ash.

\section{INTRODUCTION}

A kind of the volcanic ashes called "Shirasu", abundantly deposited due to a big pyroclastic flow in the Southern Kyushu, Japan, which happened 20 to 100 thousand years ago, is one of the unused natural resources. Shirasu is unsuitable for agriculture due to excessive water drainage, and poses a heavy damage every year as a sediment disaster. In order to use Shirasu which may causes sediment disaster and serious damage to the crops, various areas had been investigated to find its promising application [1], [2]. In view of this matter, we provide the formation of silicon ( $\mathrm{Si}$ ) from Shirasu volcanic ash, as a starting material.

$\mathrm{Si}$ is used as an alloy element in steel industries and metallurgical companies. $\mathrm{Si}$ is used for the production of solar cells and electronic devices [3]. All those products are produced on a commercial scale by conventional carbothermal processes. The overall reaction of Si production using silica with carbon is shown by the following equation.

$$
\mathrm{SiO}_{2}(s)+2 \mathrm{C}(s)=\mathrm{Si}(s)+2 \mathrm{CO}(g)
$$

In industry, $\mathrm{Si}$ is mainly produced by silica and carbon at $1900{ }^{\circ} \mathrm{C}$ [4]. It is an energy intensive process. To produce at low cost, Wang, et al. reported the reaction of silica with aluminum metal at $1480{ }^{\circ} \mathrm{C}$ [5]. And Bao, et al. also reported magnesiothermic reduction process at $650{ }^{\circ} \mathrm{C}$ [6]. In this way, there are many studies to produce $\mathrm{Si}$ at low cost.

On the other hand, in recent years, the interest regarding renewable energy has been growing due to the decrease in fossil fuels and the global warming. With a view of growth in the world's population, the demand for energy is always

\footnotetext{
Manuscript received February 25, 2015; revised June 1, 2015.

The authors are with the Faculty of Engineering, University of Miyazaki, (e-mail:

hkaneko.ee@cc.miyazaki-u.ac.jp,nishioka@cc.miyazaki-u.ac.jp)
} Japan growing, while the fossil fuel reserves, in particular of oil, are in the stake of exhaustion [7]. That is why, the use of clean, safe and cost-effective energy supplies need to be increased. Solar energy which has an intensity of $1000 \mathrm{~W} / \mathrm{m}^{2}$, has an important role to play within this framework, as it may also be used in solar furnace application. The solar furnace is possible to produce high temperature in a short period of time by utilizing Fresnel lens as a sunlight concentrator. Through this method, a new production process to create materials that require to be done under high temperature condition with regards of the shortage of energy resources has been significantly provided [8]-[11].

In the actual process of the $\mathrm{Si}$ formation, three reactions take place,

$$
\begin{aligned}
& \mathrm{SiO}_{2}(s)+C(s)=\mathrm{SiO}(g)+\mathrm{CO}(g) \\
& \mathrm{SiO}(g)+2 \mathrm{C}(s)=\mathrm{SiC}(s)+\mathrm{CO}(g) \\
& \mathrm{SiO}(g)+\mathrm{SiC}(s)=2 \mathrm{Si}(s)+\mathrm{CO}(g)
\end{aligned}
$$

$\mathrm{SiO}$ is easily produced by the reaction (2) near $1100{ }^{\circ} \mathrm{C}$. Then SiC formation occurs through reaction (3) above $1300{ }^{\circ} \mathrm{C}$. Estimation of Gibbs free energy $(\Delta \mathrm{G})$ indicates that reaction (4) takes place above $1700^{\circ} \mathrm{C}$, but $\Delta \mathrm{G}$ of reaction (3) is lower than that of the reaction (4). If $\mathrm{SiO}_{2}$ and $\mathrm{C}$ exist in the reaction system, reaction (3) takes place preferentially [12]. In view of this matter, we provide the formation of $\mathrm{Si}$ by silica and $\mathrm{SiC}$ fabricated using Shirasu.

In this study, instead of requisite thermal energy, we prepared a Si using the solar furnace that produced an ultrahigh temperature condition by utilizing a Fresnel lens as a sunlight concentrator. The $\mathrm{Si}$ was prepared by silica and $\mathrm{SiC}$ formed using Shirasu. There is no report which forms the semiconductor material of high value like $\mathrm{Si}$ by using environment-friendly concentrated sunlight. We prepared a $\mathrm{Si}$ using the solar furnace that produces an ultrahigh temperature condition by utilizing a Fresnel lens as a sunlight concentrator.

\section{EXPERIMENTAL PROCEDURE}

Fig. 1 shows the solar furnace created in this study. The solar furnace was composed by two parts; Fresnel lens and reacting furnace. In solar thermal conversion applications, Fresnel lens has the advantages of small volume, light weight, suitable for mass productions at low cost, and effectively increasing the energy density. The material of the Fresnel lens was PMMA, and it had an area of $1.40 \mathrm{~m} \times 1.05 \mathrm{~m}$. Fig. 2 schematically shows the reacting furnace. The reacting furnace was composed of a cylindrical vacuum chamber 
(diameter: $20.3 \mathrm{~cm}$, depth: $19.2 \mathrm{~cm}$ ) and quartz glass plate functioning to guide the concentrated sunlight into the furnace, and we put a thermal insulation and crucible, at the Fresnel lens' focal point.

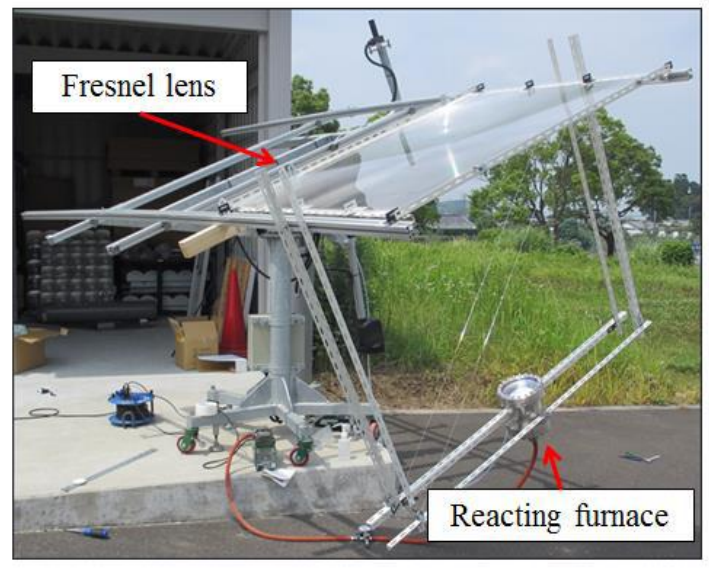

Fig. 1. Solar furnace system.

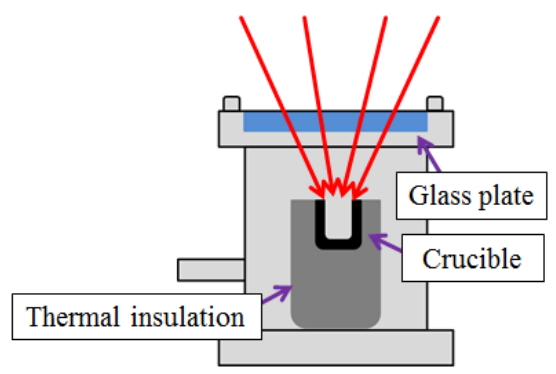

Fig. 2. Schematic of reacting furnace.

The sample was made from a mixture of silica formed using Shirasu volcanic ash [13], [14] and SiC fabricated using silica and graphite [15], and placed in the carbon crucible inside the reacting furnace. The high purity nanoporous silica was fabricated using Shirasu volcanic ash as a starting material. The materials with Shirasu were melted at $1400^{\circ} \mathrm{C}$. A mother glass was formed by quenching the melt in pure water. Leaching was performed by immersing the mother glass into an $\mathrm{HCl}$ solution. Non-silica phases formed by phase separation in the mother glass were leached out with acid solution. The obtained porous silica was more than $99 \%$ pure [13], [14].

After that, the air inside the reacting furnace was discharged so that it was in the vacuum condition. Then the Ar gas was left to flow into the reacting furnace until it reaches $0.1 \mathrm{MPa}$. Next, the sample was irradiated with the high concentrated sunlight for 3.5 hours at about $2000{ }^{\circ} \mathrm{C}$. The temperature at the focal point was measured by the Infrared Radiation Thermometer (CHINO, IR-CAS2) at 11 AM of 27 November 2014. Figure 3 shows the direct normal irradiance (DNI) during the experiment. The circle of the Fig. 3 shows the time when we measured the temperature using the Infrared Radiation Thermometer. DNI was stable and high with approximately $890 \mathrm{~W} / \mathrm{m}^{2}$ during the experiment. The solar furnace system uses the Fresnel lens to collect sunlight and focuses it onto the reacting chamber. The system can only use the direct beam component of sunlight. Since the solar furnace is equipped with the sun tracking system, temperature of the furnace depends on the intensity of DNI.
Therefore, it is necessary to irradiate the sample using a stable and high DNI. The reason of the drop of DNI in Fig. 3 was temporal cloudiness. While the Ar gas kept on flowing at $2 \mathrm{~L} / \mathrm{min}$ into reacting furnace. After the irradiation process, the furnace was left until the sample was cooled down to room temperature under $\mathrm{Ar}$ atmosphere in order to avoid oxidization of the carbon crucible. Finally, the sample was evaluated by X-ray diffraction (XRD, PANalytical, X'Pert PRO).

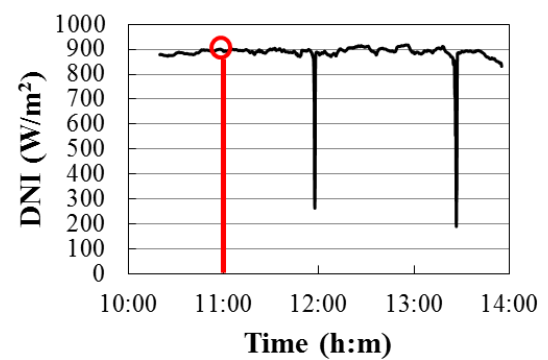

Fig. 3. Direct normal irradiance (DNI) during the experiment.

\section{RESUlTS AND DisCUSSION}

Fig. 4 shows the image of the sample inside the carbon crucible after the irradiation process. From the figure, it was confirmed that the dent ("Irradiated portion" in the Fig. 4) was formed on the center of the sample, where the highly concentrated sunlight hit. This particular part (irradiated portion) of the sample was analyzed using XRD.

Fig. 5 shows XRD pattern of the sample after the irradiation process. The results of XRD analysis showed that the silica and $\mathrm{SiC}$, which were prepared by using Shirasu volcanic ash, and other three diffraction peaks were appeared. The three diffraction peaks that labeled with (111), (220) and (311) were considered as the characteristic of Si [16]. From XRD results, the sample was found to have produced the $\mathrm{Si}$ component. However, the Si peak that labeled with (111) is weaker than the $\mathrm{SiC}$ (111) peak. The sample included a small amount of Si.

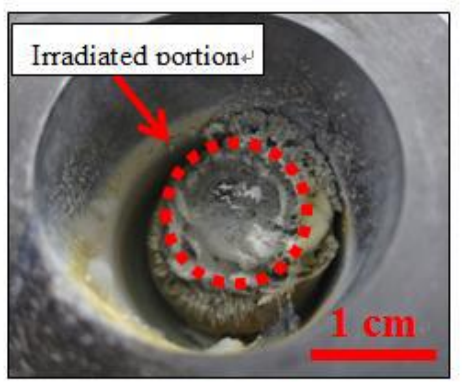

Fig. 4. Image of sample inside the carbon crucible.

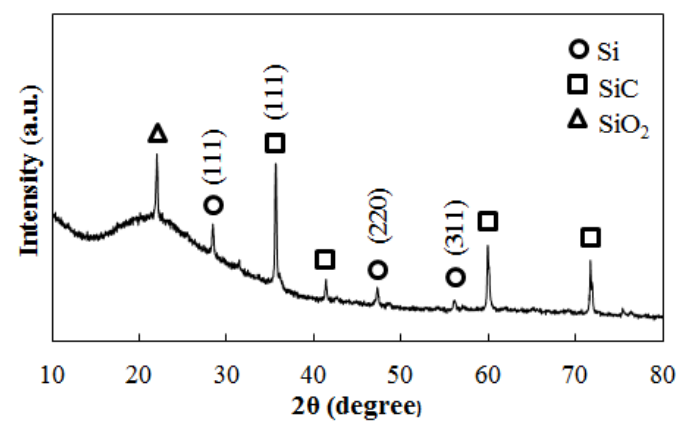

Fig. 5. X-ray diffraction pattern of the sample after irradiation.

Fig. 6 shows the image of the scaffolding on the furnace 
wall after the irradiation process. The color of the scaffolding was yellow. The large quantity of the scaffolding was obtained every experiment. The scaffolding was analyzed using XRD.

Fig. 7 shows XRD pattern of the scaffolding after the irradiation process. The results of XRD analysis showed that the silica and other three diffraction peaks were appeared. The three diffraction peaks that labeled with (111), (220) and (311) were considered as the characteristic of Si. From XRD results, the sample was found to have produced the $\mathrm{Si}$ component. There was no peak of SiC. It is considered that a chemical vapor deposition occurs in the reacting furnace. $\mathrm{SiO}$ and carbon gases generated by the reaction of the sample inside the carbon crucible and high temperature produced $\mathrm{Si}$ on the furnace wall.

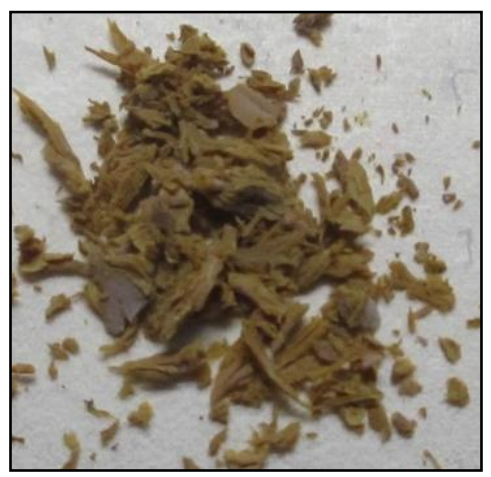

Fig. 6. Image of the scaffolding on the furnace wall after the irradiation process.

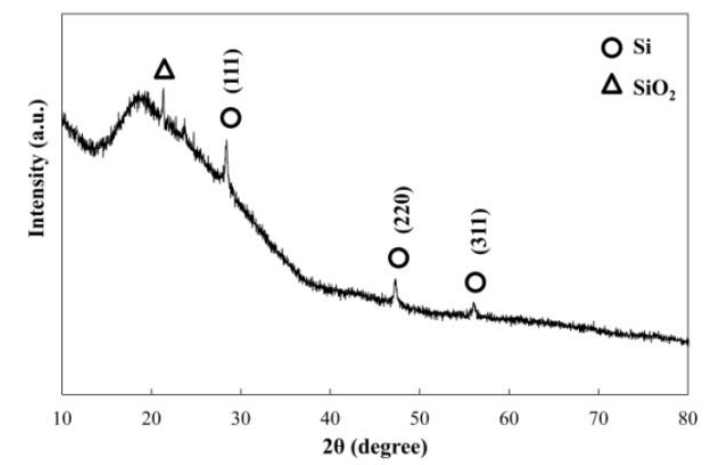

Fig. 7. X-ray diffraction pattern of the scaffolding on the furnace wall after the irradiation process.

\section{CONCLUSION}

Silicon was prepared from Shirasu volcanic ash using solar furnace. The solar furnace was composed by two parts; Fresnel lens and reacting furnace. The material of the Fresnel lens was PMMA, and it had an area of $1.40 \mathrm{~m} \times 1.05 \mathrm{~m}$. The reacting furnace was composed of a cylindrical vacuum chamber and quartz glass plate functioning to guide the concentrated sunlight into the furnace, and we put a thermal insulation and crucible, at the Fresnel lens' focal point. The sample was made from a mixture of silica formed from Shirasu volcanic ash and $\mathrm{SiC}$ fabricated using silica and graphite, and placed in the carbon crucible inside the reacting furnace.

We have successfully prepared $\mathrm{Si}$ from silica and $\mathrm{SiC}$, which were fabricated from Shirasu volcanic ash, using the solar furnace, never been performed before. However the sample included a small amount of Si. In order to form a large quantity of $\mathrm{Si}$, the longer irradiation time will be necessary.

The method implemented in this study could effectively avert the shortage of energy resources in contrast to the traditional process for the formation of $\mathrm{Si}$. This method is expected to be the valid utilization method of Shirasu volcanic ash as a natural resource, to form superior materials using renewable energy.

\section{ACKNOWLEDGMENT}

A part of this work was supported by INAMORI FOUNDATION. We would like to thank Kouji Maeda of University of Miyazaki for valuable discussion.

\section{REFERENCES}

[1] T. Yamaguchi, K.Takewaka, and S. Mori, "Durability monitoring on RC structures using "Shirasu concrete" in marine environment," in Proc. the 6th International Conference on Concrete under Severe Conditions, 2010, vol. 1, pp. 209-216.

[2] M. Kukizaki, "Relation between salt rejection and electrokinetic properties on Shirasu porous glass (SPG) membranes with nano-order uniform pores," Separation and Purification Technology, vol. 69, pp. 87-96, September 2009.

[3] J. C. S. Pires, A. F. B. Braga, and P. R. Mei, "Profile of impurities in polycrystalline silicone samples purified in an electron beam melting furnace," Solar Energy Materials and Solar Cells, vol. 79, pp. 347-355, September 2003.

[4] B. G. Gribov and K. V. Zinov'ev, "Preparation of high-purity silicon for solar cells," Inorganic Materials, vol. 39, pp. 653-662, July 2003.

[5] L. L. Wang, Z. A. Munir, Y. M. Maximov, "Thermite reactions: their utilization in the synthesis and processing of materials," Journal of Materials Science, vol. 28, pp. 3693-3708, July 1993.

[6] Z. Bao, M. R. Weatherspoon, S. Shian, Y. Cai, P. D. Graham, S. M Allan, G. Ahmad, M. B. Dickerson, B. C. Church, Z. Kang, H. W Abernathy, C. J. Summers, M. Liu, and K. H. Sandhage, "Chemical reduction of three-dimensional silica micro-assemblies into microporous silicon replicas," Nature, vol. 446, pp. 172-175, March 2007.

[7] A. A. Abdurakhmanov, K. K. Zainutdinova, M. A. Mamatkosimov, M S. Paizullakhanov, and G. Saragoza, "Solar Technologies in Uzbekistan: State, priorities, and perspectives of development," Applied Solar Energy, vol. 48, pp. 84-91, April 2012.

[8] A. A. Abdurakhmanov, U. F. Turaeva, and S. I, Klychev, "Methodology of determining integral radiant emittance of solar radiation receivers," Applied Solar Energy, vol. 45, pp.114-115, June 2009.

[9] T. P. Salikhov, V. V. Kan, E. M. Urazaeva, T. V. Savatyugina, and G. M. Arushanov, "Prospects for application of superdispersed powders obtained in small solar furnaces to form ceramic membranes," Applied Solar Energy, vol. 47, pp. 146-148, June 2011.

[10] R. K. Rakhimov, R. A. Muminov, and T. T. Riskiev, "Application of functional ceramics synthesized in a large solar furnace for the synthesis of complex compounds," Applied Solar Energy, vol. 48, pp. 47-50, January 2012.

[11] S. A. Faiziev, M. S. Paizullakhanov, E. Z. Nodirmatov, R. Yu. Akbarov, and M. A. Zufarov, "Synthesis of pyroxene pyroceramics in large solar furnace with $\mathrm{ZrO} 2$ crystallization nucleator," Applied Solar Energy, vol. 44, pp. 139-141, June 2008.

[12] T. Okutani, "Utilization of silica in rice hulls as raw materials for silicon semiconductors," Journal of Metals, Materials and Minerals, vol. 19, pp. 51-59, 2009.

[13] K. Sato, T. Kokubu, and K. Nishioka, "Effect of heat treatment on high purity nanoporous silica formed from volcanic ash deposit shirasu," Advanced Materials Research, vol. 747, pp. 547-550, August 2013.

[14] K. Sato, T. Kokubu, and K. Nishioka, "Control of pore size of high purity Nanoporous silica formed from volcanic ash deposit shirasu," Advanced Materials Research, vol. 622-623, pp. 970-974, December 2012.

[15] K. Sato, K. Maeda, and K. Nishioka, "Proposition of a new valid utilization for Shirasu volcanic ash using renewable energy," Advanced Materials Research, vol. 894, pp. 149-153, February 2014.

[16] L. Batchelor, A. Loni, L. T. Ganham, M. Hasan, and J. L. Coffer, "Manufacture of mesoporous silicon from living plants and agricultural waste: An environmentally friendly and scalable process," Silicon, vol. 4, pp. 259-266, October 2012. 


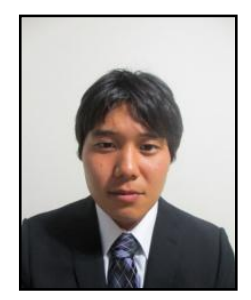

Keisuke Hatakeyama was born in Chiba, Japan, in 1990. He received the bachelor degree in engineering from University of Miyazaki, Miyazaki, Japan, in 2014. He is currently a master candidate student at University of Miyazaki, Miyazaki, Japan. He is interested in the field of renewable energy, solar cells, and concentrated sunlight.

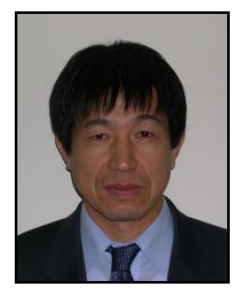

Hiroshi Kaneko was born in Fukuoka, Japan, in 1964 He received the bachelor, master and Ph.D. degrees from Tokyo Institute of Technology, Japan, in 1987, 1989 and1993, respectively, all in chemistry. Since 2013, he has been a professor in research center for Sustainable Energy \& Environmental Engineering, Faculty of Engineering, University of Miyazaki, Japan. His research interests include in the field of solar chemistry, solar energy conversion into chemical energy via thermochemical reaction.

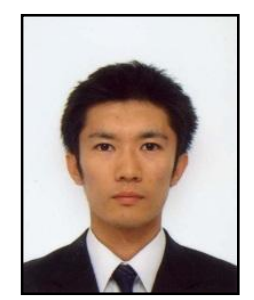

materials science.
Kensuke Nishioka was born in Kyoto, Japan, in 1975. $\mathrm{He}$ received the bachelor degree in engineering from Osaka University, Osaka, Japan, in 1998 and the master and Ph.D. degrees from Nara Institute of Science and Technology (NAIST), Nara, Japan, in 2001 and 2004, respectively, all in materials science. Since 2007, he has been an associate professor in Department of Applied Physics, Faculty of Engineering, University of Miyazaki, Japan. His research interests include in the field of solar cell, 